\title{
SABERES PRÁTICOS NA FORMAÇÃO DO ENFERMEIRO
}

Luciana Guimarães Assad*

Lígia de Oliveira Viana**

\section{Resumo}

O estudo, realizado com enfermeiros do Hospital Universitário Pedro Ernesto, se propôs a refletir sobre os saberes práticos, na formação do enfermeiro. Na construção do referencial teórico, foram muito relevantes as contribuições de Patricia Benner, Phillipe Perrenoud e Donald Shön. Do ponto de vista metodológico, constituiu-se de estudo de caso, com abordagem qualitativa; a partir de entrevistas semi-estruturadas com enfermeiros assistenciais. Os resultados demonstram que, as competências que dão suporte ao exercício profissional são construídas a partir dos saberes práticos, dos conhecimentos teóricos, da experiência de vida e da socialização profissional.

Descritores: educação continuada em enfermagem; competência clínica; competência profissional

\begin{abstract}
The study, carried through with nurses at the University Hospital Pedro Ernesto, looked to reflect on practical knowledge in the formation of the nurse. In the construction of the theoretical referential, the contributions of Patricia Benner, Phillipe Perrenoud and Donald Shön have been very relevant. From a methodological point of view, it consisted of a case study, with a qualitative approach; from semi-structured interviews with nurses involved in assisting the patient. The findings demonstrate that the competences that support the professional exercise are built on practical knowledge, theoretical knowledge, life experience, and professional socialization.

Descriptors: continued nursing education; clinical competence; professional competence

Title: Practical knowledge in the formation of the nurse
\end{abstract}

\section{Resumen}

El estudio, realizado con los enfermeros del Hospital Universitario Pedro Ernesto, se propuso reflexionar sobre los saberes prácticos, de la formación del enfermero. En la construcción del referencial teórico, fueron muy relevantes las contribuciones de Patricia Benner, Phillipe Perrenoud y Donald Shon. Desde el punto de vista metodológico, está constituida de un estudio de caso, con abordaje cualitativo; a partir de entrevistas semiestructuradas con enfermeros asistenciales. Los resultados demostraron que, las competencias que dan soporte al ejercicio profesional se construyen a partir de los saberes prácticos, de los conocimientos teóricos, de la experiencia de la vida y de la socialización profesional.

Descriptores: educación continua en enfermería; competencia clínica; competencia profesional

Título: Saberes prácticos en la formación del enfermero

\section{Introdução}

A partir da experiência pessoal, entendemos que a formação do enfermeiro atuante na área hospitalar está diretamente relacionada à sua experiência assistencial. Os resultados do processo formativo podem ser mais ou menos fecundos, de acordo com a intensidade e fundamentação teórica, que alicerça a reflexão sobre as ações. Quando sistemática, intensa e crítica, facilita avanços no sentido de conhecer a si mesmo e ao ambiente que o cerca, desenvolver o poder de argumentação, a capacidade de equilibrar teoria e prática e, finalmente, intercambiar experiências com a equipe.

Co-existem nesse movimento o conhecimento teórico e a experiência prática, cuja transação gera conhecimento pessoal e particular e coletivo. Cada profissional traz para o ambiente educativo, as peculiaridades de seu potencial intelectual, conhecimentos apreendidos e a bagagem de experiências adquiridas ao longo de sua história de vida pessoal e acadêmica. Nesse processo, é compreensível que haja diferenças na facilidade de movimentar-se e refletir criticamente sobre as diversas situações com que se defrontam os enfermeiros, na prática. A integração do conhecimento pessoal e experiência no trabalho interfere decisivamente nas escolhas relativas aos cuidados a serem prestados aos clientes.

Decorre do exposto que o enfermeiro não constrói conhecimentos somente por meio de estudos acadêmicos, mas o reconstrói no dia-a-dia, a partir dos desafios da realidade. Ao transformar o saber teórico em prática assistencial, está construindo novo conhecimento; reelabora antigas aprendi- zagens, segundo critérios derivados do cotidiano da assistencial.

Assim concebido, o trabalho do enfermeiro pode ser visto como princípio educativo, a ser explorado no processo de formação profissional permanente, o que propicia subsídios à formulação de políticas institucionais para educação continuada.

Através da experiência, o profissional constrói o seu conhecimento, definido como o conjunto de esquemas de pensamento e de ação de que dispõe um ator. Esse processo determinará as suas percepções, interpretações e as direcionará na tomada de decisões que Ihe permitirão enfrentar os problemas do cotidiano de trabalho. Para que o conhecimento gere competências, é necessário que os saberes dos profissionais sejam mobilizados através de seus esquemas de ações, decorrentes da percepção, avaliação e decisão, desenvolvidos na prática ${ }^{(1,2)}$

Apesar dessa concepção teórica ser dominante no contexto mundial relativo à formação profissional, nossa atuação na área da educação continuada, ainda apresenta lacunas no que concerne a incluir a aprendizagem como elemento de discussão e de reflexão, enquanto se trabalha. Via de regra, os programas de atualização concentram-se em atividades de treinamento, operacionalizadas por meio de cursos sobre temas pontuais, privilegiando-se a racionalidade técnica.

Para reverter esse equívoco, como assinalamos, fazse necessário combinar teoria e prática e, desse modo transformar o ambiente de trabalho em laboratório de aprendizagem, provendo-o de infra-estrutura para partilhar,

* Enfermeira. Doutora em Enfermagem pela EEAN/UFRJ. Coordenadora do Curso de Graduação em Enfermagem da Universidade Estácio de Sá Campus Barra-Akxe. Enfermeira do Hospital Universitário Pedro Ernesto/UERJ.

** Professora Adjunta do Departamento de Metodologia de Enfermagem da EEAN/UFRJ.Doutora em Enfermagem pela Escola de Enfermagem Anna Néry/UFRJ

E-mail do autor: lassad@terra.com.br 
construir e divulgar o conhecimento profissional.

Estudos na área de enfermagem vêm sendo realizados com esse enfoque. Neste sentido, destacamos uma dissertação de mestrado que trata da relação teoria e prática, e que teve por objeto as vivências da enfermeira recém-formada, na prática hospitalar. Seus achados remetem, entre outros, às dificuldades de ordem técnica e teórica, encontradas pelas enfermeiras no ambiente do trabalho; à ambigüidade relacionada às suas funções; à adaptação do conhecimento apreendido no meio acadêmico à realidade encontrada e à atribuição de funções profissionais que não Ihes são pertinentes. Partindo dessas evidências, a autora concluiu que a formação acadêmica propicia a base para que o enfermeiro possa atuar junto ao cliente, mas somente o cotidiano da prática parece ser capaz de oferecer a experiência necessária para fortalecer esse conhecimento(3).

Entender o trabalho como fonte de formação é compreendê-lo como parte da vida do ser humano e como estrutura que influencia a composição do ser no plano individual, assim como o núcleo familiar, a escola ou outras instituições que venham a fazer parte de sua vida. A formação é um processo amplo e não se limita ao simples desenvolvimento de aptidões e faculdades, mas tem uma amplitude que se refere a um "processo de construção e realização de um Eu em ascensão, esforçado em adquirir consciência do mundo e apreendê-lo em sua essência" (4:85).

Apoiadas no pressuposto de que existe diferença entre teoria e prática, apesar de esses conceitos evidenciarem relação umbilical, pensamos que se torna necessária intensificar estudos sobre a formação do enfermeiro na prática hospitalar, discutindo criticamente a continuidade da sua formação profissional. Com tal propósito, desenvolvemos estudo cujo objetivo foi refletir sobre a influência dos saberes práticos na formação do enfermeiro.

Considerando a natureza desse objeto, optamos por estudo qualitativo, do tipo descritivo, que tomou como cenário o Hospital Universitário Pedro Ernesto (HUPE), unidade hospitalar inserida no complexo da Universidade do Estado do Rio de Janeiro (UERJ). Na operacionalização da investigação, entrevistamos seis enfermeiros atuantes na assistência direta ao cliente, o que constituiu o critério de escolha dos sujeitos juntamente com a definição da área de atuação ficando estabelecido dois enfermeiros de cada Serviço: Enfermagem Cirúrgica, Enfermagem Clínica e Enfermagem da Mulher e da Criança.

Na entrevista utilizamos como perguntas norteadoras: Quais são as fontes de aprendizagem que possibilitam o desenvolvimento de suas ações na prática? Como você acredita que acontece a aprendizagem na sua prática assistencial? Como você percebe a relação teoria e prática na sua aprendizagem? Descreva sucintamente uma situação de prática vivenciada em que você percebeu que houve aprendizagem. Você tem o hábito de refletir sobre as suas ações na assistência? Em que situações desenvolve essa habilidade? Em que situações deixa de desenvolver? Na sua opinião que fatores contribuem para diminuir e incrementar a aprendizagem do enfermeiro na prática?

É importante esclarecer, que o estudo respeita, em todos os seus aspectos, a Resolução $n^{\circ} 196 / 96$ sobre Pesquisa Envolvendo Seres Humanos. Desta maneira, respeitamos os princípios éticos que implica no consentimento livre e esclarecido dos indivíduos-informantes e a proteção de grupos vulneráveis e aos legalmente incapazes; ponderação entre risco e benefício, comprometendo-se com o máximo de benefícios e o mínimo de riscos; relevância social da pesquisa, o que garante igual consideração dos interesses envolvidos, não perdendo o sentido de sua destinação no que tange a justiça e a eqüidade.

De acordo com os objetivos estabelecidos para o estudo e o método escolhido, os dados foram trabalhados agrupando-os por categorias de análise. Foi realizada uma confrontação entre todos os dados produzidos a fim de analisálos criticamente, buscando explicações para os fatos.

Para dar suporte à análise utilizamos como referencial teórico, a prática reflexiva de Donald Shön, os estudos sobre formação profissional desenvolvidos por Phillippe Perrenoud e a análise das práticas de enfermeiros desenvolvido por Patrícia Benner.

\section{$2 \mathrm{~A}$ aprendizagem no ambiente de trabalho}

Como referido, o propósito orientou-se para refletir sobre os saberes práticos na formação do enfermeiro. Definimos saberes práticos como o conjunto de instrumentos aos quais os enfermeiros recorrem no dia-a-dia do exercício da profissão; em outras palavras, abrange o conjunto de conhecimentos elaborados pelo próprio enfermeiro, a partir das suas experiências na labuta cotidiana. Eis porque assumimos que não se pode admitir a existência de um único saber, na prática assistencial. Isso porque, na prática, o enfermeiro recorre a um saber acadêmico, ético, cultural, multifacetado; enfim, ele relaciona a teoria e a prática em seu dia-a-dia.

Ao se organizar para realizar uma intervenção, o profissional não pode fazer abstração daquilo que a ciência diz sobre as condições dessa intervenção. Porém, depois de uma experiência mais longa na prática, o saber acadêmico ocupa plano secundário, em favor da prática profissional, que se torna a primeira referência, na conduta empreendida pelo trabalhador a fim de prestar cuidados e dar continuidade à construção de suas competências ${ }^{(1,5)}$.

Tal perspectiva pode ser confirmada, por meio de observações do cotidiano e de manifestações verbais de colegas, militantes da Enfermagem. Para ilustrar, transcrevemos o depoimento de uma participante de nossa pesquisa, que detinha dezesseis anos de experiência na área de enfermagem: ... o peso maior é da prática, onde você vivencia e atua a teoria, você consegue colocá-la na prática... você vivencia $o$ ato de fazer, de ver.... (entrevista 1)

Essa evolução do saber teórico, a partir de sua aplicação na prática, acontece progressivamente, à medida que se avança no ciclo da vida profissional. Em outra entrevista, a enfermeira, com dezessete anos de experiência em Neonatologia, exemplificou as mudanças que ocorrem com o profissional experiente, a partir do conceito de prematuridade. Para ela, quando um enfermeiro pouco experiente se prepara para receber um prematuro em sua unidade, ele se baseia em conhecimentos teóricos que, supostamente, prevêem todas as necessidades possíveis desse cliente; então um aparato imenso é organizado. Agora quando você tem experiência tudo fica mais fácil (entrevista 3). Na sua concepção, a facilidade decorre das conclusões acerca das diferenças evidentes entre os prematuros, obtidas a partir das observações desenvolvidas no ambiente de prática da Neonatologia:

\footnotetext{
..mas aí a gente pergunta para o pediatra se a criança que vai chegar tem algum comprometimento, se existe um ultra-som dessa criança......porque não quer dizer que todo prematuro vai apresentar aquele problema... (entrevista 3)
}

Segundo esse enfoque, fica mais claro porque o profissional recém-formado evidencia apego mais forte às teorias, técnicas e modelos de cuidado. À medida que opera na prática, os saberes teóricos vão sendo resignificados, de tal forma que sua rotina é reconstruída em novas bases, mais 
sólidas e consistentes. A esse respeito, são ilustrativos os depoimentos apresentados a seguir:

... você sai da graduação com alguma teoria e pouca prática...... prática contesta a teoria porque nem tudo acontece daquele jeito que está ali escrito, fechadinho......então você passa a refletir mais sobre a sua teoria...... (entrevista 3)

Nessa movimentação entre saberes teóricos e práticos dos enfermeiros, a experiência não significa a mera passagem do tempo, eis que representa o refinamento de noções e teorias preconcebidas através do encontro com várias situações da prática que adicionam nuances à teoria. Quando o enfermeiro é classificado como especialista, ele consegue abandonar as regras e tornar melhor e mais ágil, pois as suas habilidades são transformadas trazendo aperfeiçoamento profissional. Se alguém insiste para que o enfermeiro especialista use totalmente de regras e guidelines em suas atividades, sua performance tende a diminuir(6).

Percebemos que as decisões implementadas pelo enfermeiro na prática assistencial são desenvolvidas a partir de uma articulação entre as situações vividas, as teorias que são apresentadas aos profissionais e que tentam explicar a sua prática.

Por esse motivo, que as formações que têm como eixo principal teorias descoladas da realidade fazem com que o futuro profissional não possa retomar tais conceitos posteriormente quando ele se situa na prática. Decorre desse fenômeno uma grande distância entre a formação acadêmica (que acaba se revelando inútil) e uma prática intuitiva que corresponde aos imprevistos e aos problemas do momento, dando a impressão de um eterno recomeçar ${ }^{(2)}$

Sob esse enfoque, compreendemos que a teoria oferece o que pode ser claramente explícito e compreendido por todos, enquanto que a prática assistencial por sua complexidade e singularidade, é mais rica e produtiva, no sentido de aprendizagens significativas. Por isso, a movimentação e o diálogo entre prática e teoria geram o refinamento necessário para que o enfermeiro desenvolva suas ações com autonomia. A compreensão dessa situação e a reflexão sobre a mesma conduzem o enfermeiro ao abandono de regras artificiais, impostas eventualmente pelos manuais e à conseqüente criação de seu próprio esquema de ação, tornando mais ágil e melhor qualificada a assistência que presta aos clientes.

Nessa construção dos saberes, modificações ocorrem nos saberes procedimentais: alguns se extinguem, simplesmente por falta de uso; outros se incorporam à rotina e ampliam o habitus e, finalmente, outros ainda permanecem como representações vivas "porque são mantidos nesse nível pela complexidade e pela resistência do real ou por um investimento particular"(2:156)

Na depuração dos saberes, desenvolvida na interação com o ambiente, construímos nossas competências para o trabalho, compreendidas como o "conjunto diversificado de conhecimentos da profissão, de esquemas de ação, de posturas que são mobilizados no exercício do ofício" (2:156). De acordo com essa definição bem ampla, as competências são, ao mesmo tempo, de ordem cognitiva, afetiva, conativa e prática.

Nessas condições, desenvolvemos nosso habitus, constituído pelo conjunto de nossos esquemas de percepção, de avaliação, de pensamento e de ação. O habitus permite que sejamos capazes de enfrentar uma grande diversidade de situações cotidianas, é o determinante de nossas ações e está diretamente relacionado com os nossos saberes ${ }^{(2)}$.

Assim sendo, compreendemos que, a partir da prática, alguns de nossos saberes interiorizam-se, automatizam-se e incorporam-se ao que Piaget denomina de "inconsciente prático", tornando-se um hábito(2:207).

É pertinente acrescentar que, pelo fato da instituição que tomamos como cenário de nossa pesquisa estar situada no contexto universitário existe um enfrentamento entre enfermeiros docentes e assistenciais, como resultado concreto da discussão em torno dos aspectos relacionados à teoria e à prática, como não deixa dúvidas o depoimento a seguir:

... eu vejo no hospital por ser universitário: quando entra um grupo de alunos com o professor, o líder fica com um pé na frente e outro atrás, com medo eu acho, que eles façam alguma análise de sua prática, entendeu?... Eles não podem ter medo disso porque a prática deles pode até melhorar a teoria do professor, e a teoria dele pode melhorar a prática do enfermeiro, mas não... nunca ficam ligados na questão...(entrevista 2)

Buscando compreender a relação entre docentes e assistentes, é forçoso reconhecer que suas práticas são semelhantes, mas possuem enfoques diferenciados. Ambos, num ambiente de hospital universitário, cuidam e ensinam; porém, o foco do docente é o aluno e o do assistencial o cliente. Trata-se de relação complexa, porque cada pólo da equação tem peculiaridades que demandam tratamento particularizado, embora sejam interdependentes. Se essa interação for devidamente compreendida e trabalhada, no sentido da comunicação produtiva e integrada, a aprendizagem pode ser amplamente enriquecida.

Aprender a fazer é enfrentar progressivamente a complexidade e dispor de um enquadramento (mecanismo cognitivo e afetivo que permite uma visualização da situação a partir de outra ótica) que conduz o profissional à reflexividade, $\mathrm{a}$ falar de suas dúvidas e de seus medos, a buscar um apoio ou conselho, dar sentido às vivências práticas e, dessa forma, confrontar com outros atores, ampliando a sua fonte de aprendizagem, adquirindo novas e enriquecedoras experiências ${ }^{(2)}$

Se aceitamos que o percurso de formação desses enfermeiros para o aprendizado da profissão exige associação indissolúvel entre teoria e prática, decorrente da teoria, podemos admitir que a abordagem reflexiva sugere um mecanismo de formação personalizado e relacionado à realidade. A partir dessa abordagem, os enfermeiros poderão determinar continuamente suas próprias competências numa dialética permanente com os desafios da realidade. Nessa perspectiva, o encontro de enfermeiros docentes e assistenciais num espaço único, pode significar uma ampliação da possibilidade de aprendizagem, da reflexão e conseqüentemente de melhoria contínua na qualidade da assistência prestada.

Quando o profissional utiliza elementos derivados da reflexão, ele se converte em um investigador, no próprio contexto prático. Assim procedendo, ele não dependerá das categorias e técnicas estabelecidas, porque será capaz de construir novas categorias de interpretação e abordagem de cada caso vivido; ele não irá separar pensamento e ação, pois o seu experimento é um tipo de ação.

Durante o aprendizado, e suas interações com a prática, o profissional desenvolve suas competências essencialmente na prática e a partir da prática, o que distingue a reflexão na ação e para a ação. A primeira demonstra que o profissional, em seu ambiente de trabalho, emite uma resposta rotineira a determinada situação, se surpreende com as conseqüências de sua ação (elemento surpresa diferente do imaginado), reflete sobre os acontecimentos e experimenta nova ação, para resolver o problema. No segundo caso, a reflexão para ação, o prático pode igualmente refletir sobre a ação difundida, analisando e tirando partido da experiência passada. Segundo interpretação do autor mencionado, é a prática e suas 
respostas às ações desenvolvidas, que suscita e valida novas condutas $^{(1)}$

No curso da reflexão do profissional (antes, durante e após a ação), ele utiliza representações e saberes de fontes distintas, dando origem às competências profissionais. Segundo essa perspectiva analítica, a formação deveria visar não somente ao desenvolvimento de representações e de teorias, mas especialmente ao enriquecimento dos esquemas de ação( ${ }^{(2)}$.

Decorre do exposto que aprender para a prática significa que valorizamos essencialmente os aprendizados que têm incidência direta sobre a nossa vida profissional.

Ainda que a reflexão na ação seja um processo extraordinário para a aprendizagem, ele não é um acontecimento freqüente, visto que o profissionalismo ainda está centrado na técnica e a reflexão ainda não é aceita como forma legítima de conhecimento profissional(2).

\section{Considerações finais}

Tanto para os profissionais experientes, quanto para os iniciantes, não há dúvida de que, sem disciplina intelectual sem rigor e sem criatividade, não há como pensarmos numa enfermagem reflexiva e autônoma, comprometida com o cuidar com qualidade, pesquisar e aprender cada vez mais, cuidando e cuidando...

A partir do que foi discutido, a hipótese que nos parece mais pertinente a orientar a formação do enfermeiro na prática assistencial é a de que a aprendizagem deve acontecer de forma que respeitemos a idiossincrasia dos sujeitos, ou seja que não utilizemos tanto de fórmulas moldadas e acabadas, mas sim que privilegiemos a maneira de construí-las na situação e entre as situações de prática. Esse modelo busca desenvolver a prática reflexiva como ponto central de aprendizagem contínua desses profissionais.

É importante criar, na formação e no local de trabalho, condições que permitam ao profissional desenvolver competências a partir da prática, através da prática e para a prática.

Por isso, entendemos que os cenários da prática assistencial devam ser valorizados como importante espaço no qual se concretizam e sedimentam os saberes dos enfermeiros. Julgamos recomendável que os Serviços de Educação Continuada possam utilizar esses valiosos saberes como elementos significativos para a continuidade da formação do profissional.

Sugerimos que enfermeiros e serviços envolvidos com a educação continuada utilizem instrumentos que busquem preencher lacunas existentes entre o conhecimento profissional e a demanda da prática, buscando a prática da reflexão desde a ação, para que os profissionais possam agir em situações de incerteza, instabilidade e conflito de valores, tendo em vista garantir a qualidade da assistência.

\section{Referências}

1. Shön DA. El professional reflexivo. Como piensam los profesionales cuando actúam. Barcelona: Paidós; 1998.

2. Perrenoud $P$, Paquay L, Altet $M$, Charlier E. Formando professores profissionais. Quais estratégias? Quais competências? Porto Alegre: Artmed; 2001.

3. Pereira MJ. Os desafios da enfermeira na prática hospitalar: os nexos com a formação acadêmica [dissertação]. Rio de Janeiro Escola de Enfermagem Anna Nery/UFRJ; 1999. 120 f.

4. Freitag B. A Teoria Crítica ontem e hoje. São Paulo: Brasiliense; 1994

5. Shön, DA. La formación de professionales reflexivos: hacia um nuevo diseño de la enseñanza y el aprendizaje en las profissiones. Madri: Ministério de Educacion y Ciencia; 1992.

6. Benner P. From novice to expert. Excellence and power in Clinical Nursing Practice. California: Addison-Wesley Publishing Company; 1984

Data de recebimento: 30/09/2002

Data de aprovação: 26/06/2003 